\title{
Hydrogen sulfide ameliorates cognitive dysfunction in streptozotocin-induced diabetic rats: involving suppression in hippocampal endoplasmic reticulum stress
}

\author{
Wei Zou ${ }^{1,2, *}$, Juan Yuan ${ }^{1,2, *}$, Zhuo-Jun Tang ${ }^{1,2}$, Hai-Jun Wei ${ }^{2}$, Wei-Wen Zhu ${ }^{2}$, Ping \\ Zhang ${ }^{1,2}$, Hong-Feng Gu ${ }^{2}$, Chun-Yan Wang ${ }^{3}$ and Xiao-Qing Tang ${ }^{1,2,4}$ \\ ${ }^{1}$ Department of Neurology, Nanhua Affiliated Hospital, University of South China, Hengyang 421001, Hunan, P.R. China \\ ${ }^{2}$ Institute of Neuroscience, Medical College, University of South China, Hengyang 421001, Hunan, P.R. China \\ ${ }^{3}$ Department of Pathophysiology, Medical College, University of South China, Hengyang 421001, Hunan, P.R. China \\ ${ }^{4}$ Hunan Province Cooperative Innovation Center for Molecular Target New Drug Study, Hengyang 421001, Hunan, P.R. China \\ *These authors have contributed equally to this work \\ Correspondence to: Xiao-Qing Tang, email: tangxq-usc@qq.com \\ Ping Zhang, email: zhangp-usc@foxmail.com \\ Keywords: cognitive dysfunction, diabetes, endoplasmic reticulum stress, hydrogen sulfide, streptozotocin \\ Received: November 04, $2016 \quad$ Accepted: April 20, $2017 \quad$ Published: July 22, 2017 \\ Copyright: Zou et al. This is an open-access article distributed under the terms of the Creative Commons Attribution License 3.0 \\ (CC BY 3.0), which permits unrestricted use, distribution, and reproduction in any medium, provided the original author and source \\ are credited.
}

\section{ABSTRACT}

Diabetes induces impairment in cognitive function. There is substantial evidence that hippocampal endoplasmic reticulum (ER) stress is involved in diabetic cognitive impairment. Hydrogen sulfide $\left(\mathrm{H}_{2} \mathrm{~S}\right)$ attenuates the learning and memory decline in experimental Alzheimer's disease and inhibits the hippocampal ER stress in homocysteine-exposed rats. Therefore, this aim of the present work was to investigate whether $\mathrm{H}_{2} \mathrm{~S}$ ameliorates the diabetic cognitive dysfunction involving inhibition of hippocampal ER stress. In the present work, we found that stretozotocin (STZ, 40 $\mathrm{mg} / \mathrm{kg}$ )-induced diabetic rats exhibited impairment in cognitive function, as judged by the novel objective recognition task (NOR) test, the Y-maze test and the Morris water maze (MWM) test. Notably, treatment of diabetic rats with sodium hydrosulfide ( $N a H S$, a donor of $\mathrm{H}_{2} \mathrm{~S}, 30$ or $100 \mu \mathrm{mol} / \mathrm{kg} / \mathrm{d}$, for $30 \mathrm{~d}$ ) significantly reversed diabetesinduced impairment in cognitive function. We also found that STZ $(40 \mathrm{mg} / \mathrm{kg})-$ induced diabetic rats exhibited hippocampal ER stress, as evidenced by upregulations of glucose regulated protein 78 (GRP78), C/EBP homologous protein (CHOP), and cleaved caspase-12 in the hippocampus. However, treatment with NaHS (30 or 100 $\mu \mathrm{mol} / \mathrm{kg} / \mathrm{d}$, for $30 \mathrm{~d}$ ) markedly suppressed the increases in GRP78, CHOP, and cleaved caspase-12 expressions in the hippocampus of diabetic rats. In addition, we noted that $\mathrm{NaHS}$ ( 30 or $100 \mu \mathrm{mol} / \mathrm{kg} / \mathrm{d}$, for $30 \mathrm{~d}$ ) significantly enhanced the generation of hippocampal endogenous $\mathrm{H}_{2} \mathrm{~S}$ in STZ-induced diabetic rats. These results suggest that $\mathrm{H}_{2} \mathrm{~S}$ exhibits therapeutic potential for diabetes-associated cognitive dysfunction, which is most likely related to its protective effects against hippocampal ER stress.

\section{INTRODUCTION}

Diabetes mellitus (DM), the most common endocrine disorder disease inducing cognitive impairment $[1,2]$, is increasing at an alarming rate and has been becoming a major public health concern [3]. Diabetics exhibit middle impairments in cognitive function and have a high risk of affective disorders, dementia and Alzheimer disease (AD) [4, 5]. Many evidence have demonstrated that the cognitive impairments is present in $30 \%$ to $40 \%$ of elderly DM patients, and the severity of cognitive impairment has a direct relationship with 
poor glycemic control in these patients [6]. Increasing evidence in diabetic animal models also demonstrated that diabetes induces cognitive impairment and memory loss [7, 8]. However, no specific approaches are able to prevent cognitive deficits induced by diabetes [9]. It play the pivotal role in development of novel therapeutic strategies to prevent the cognitive deficits in DM.

Hydrogen sulfide $\left(\mathrm{H}_{2} \mathrm{~S}\right)$, the third gaseous transmitter, exerts a series of biological and physiological effects [10-12]. Recently, a growing number of published literature indicates that $\mathrm{H}_{2} \mathrm{~S}$, acting as a neuromodulator, plays an important role in brain functions $[13,14] . \mathrm{H}_{2} \mathrm{~S}$ is shown to promote the induction of hippocampal longterm potentiation in active synapses, suggesting that $\mathrm{H}_{2} \mathrm{~S}$ could improve the learning and memory [15]. It has been demonstrated that $\mathrm{H}_{2} \mathrm{~S}$ slows down the progression of experimental $\mathrm{AD}$ and attenuates their learning and memory declines $[16,17]$. Current evidence shows that the synthesis and circulating level of $\mathrm{H}_{2} \mathrm{~S}$ decreases in the obese diabetic mice [18], streptozotocin induced type 1 diabetic mice [19], and type 2 diabetic patients [19]. Several researches have used donation of $\mathrm{H}_{2} \mathrm{~S}$ as a latent method to protect against the deterioration of diabetic complications, diabetic nephropathy and cardiomyopathy [20-22], and to improve wound healing in type 2 diabetes [23]. Therefore, we speculated that $\mathrm{H}_{2} \mathrm{~S}$ is a potential therapeutic approach for intervention of diabetes-associated cognitive defects. The objective of present researches was evaluating the possible ability of $\mathrm{H}_{2} \mathrm{~S}$ to counteract the cognitive defect in streptozotocin (STZ)exposed diabetic rats and the underlying mechanisms.

The endoplasmic reticulum (ER) is the dominating location for synthesis and maturation of secretory protein. A variety of stimulus can damage ER homeostasis and generate the store of unfolded or misfolded proteins and produced many pathological changes, namely ER stress [24]. The molecular markers of ER stress includes Glucose-regulated protein 78 (GRP78), C/EBP homologous protein (CHOP), and cleaved caspase-12. ER stress-accompanied apoptotic cell has been confirmed in various diseases, including diabetes [25]. Also, a variety of neurodegenerative disorders including AD, Parkinson disease, and cerebral ischemia involve in ER stress-induced apoptosis. [26]. The hippocampus plays a key role in certain types of learning and memory and is a crucial brain region susceptible to stress [27, 28]. Recently, the published article confirmed the hippocampal ER stress is involved in diabetic cognitive impairment [29]. Thus, inhibiting ER stress responsed in hippocampus may provide cognitive protection. In parallel to this, $\mathrm{H}_{2} \mathrm{~S}$ inhibits 6-hydroxydopamine (6-OHDA)-induced ER stress in a human neuroblastoma cell line (SH-SY5Y) [30] and cardiomyocytic ER stress in cardiomyocytic injury was demonstrated. [31]. We also recently reported that $\mathrm{H}_{2} \mathrm{~S}$ prevents hippocampus from homocysteine-arose ER stress [32]. Therefore, our present work examined whether $\mathrm{H}_{2} \mathrm{~S}$ suppresses the hippocampal ER stress in STZ-exposed diabetic rats.
In this experiment, we discovered that $\mathrm{H}_{2} \mathrm{~S}$ improved the learning and memory dysfunction of diabetic rats and prevented ER stress in the hippocampus. These findings suggested that this possibility that $\mathrm{H}_{2} \mathrm{~S}$ as a novel therapeutic approach for treatment of cognitive impairments in diabetes.

\section{RESULTS}

\section{NaHS enhances the cognitive function of diabetic rats in novel object recognition test}

To investigate whether the cognitive function of diabetic rat is impaired and whether $\mathrm{H}_{2} \mathrm{~S}$ ameliorates this impairment, we examined the cognitive function of rat using the novel object recognition test. As shown in Figure 1A, the discrimination index in STZ-exposed rats was significantly decreased compared to control. However, NaHS significantly increased the discrimination index of diabetic rats compared to the STZ-treated alone group rats $(\mathrm{F} 4,31=16.146, \mathrm{P}<0.001)$. On the other hand, NaHS (100 $\mu \mathrm{mol} / \mathrm{kg} / \mathrm{d}$, i.p.) did not affect the discrimination index of no diabetic rats. Furthermore, there was no significant discrepancy of the total exploration time between all groups $(\mathrm{F} 4,30=0.921, \mathrm{P}>0.05$; Figure 1B). These data suggested that NaHS treatment prevents the decline in cognition in diabetic rats.

\section{NaHS ameliorates the working memory impairment of diabetic rats in Y-maze test}

As an alternative method to confirm $\mathrm{H}_{2} \mathrm{~S}$ whether ameliorates working memory dysfunction, we applied the Y-maze test to assess the changes of diabetic rats in working memory functions after treatment with NaHS. Diabetic rats demonstrated an obvious decline in the correct rate compared to blank group; however, treatment of STZ-induced diabetic rats with NaHS inversed the descend in the correct rate compared to those in STZtreated alone rats $\left(\mathrm{F}_{4,30}=6.218, \mathrm{P}<0.001\right.$; Figure $\left.2 \mathrm{~A}\right)$. It should be noted that NaHS $(100 \mu \mathrm{mol} / \mathrm{kg} / \mathrm{d}$, i.p. $)$ did not affect the correct rate of rats in control group (Figure 2A). In addition, the total number of entries has no difference in various groups $\left(\mathrm{F}_{12,22}=0.992, \mathrm{P}>0.05\right.$; Figure $\left.2 \mathrm{~B}\right)$. These data also indicated that NaHS reverses the working memory dysfunction of diabetic rats.

\section{NaHS improves spatial learning and memory of diabetic rats in Morris water maze test}

To further investigate above-mentioned protective role of $\mathrm{H}_{2} \mathrm{~S}$ in cognitive dysfunction of diabetic rats, rats were received the Morris water maze task to measure the spatial learning and memory. As schematized in Figure 3A, all groups over the four training days exhibited a decrease in the escape latency. STZ-induced diabetic rats exhibited significantly higher escape latency on day 2, 3 
and 4 during training trials compared with control group rats, suggesting an obvious impairment of spatial learning function. However, treatment with NaHS significantly decreased the escape latency of STZ-induced diabetic rats from training day 2 onward. Figure 3B shows the typical swimming tracks of rats finding the underwater platform. At the 1st training day, the moving distance to search hidden platform had no difference among the five groups. At the 4th training day, diabetic rat exhibited an obvious increase in the distance swam compared with control group; however, a significant decrease emerged on NaHS -treated diabetic group in the distance swam compared to the diabetic group. There were no discrepancy of the escape latency (Figure 3A) and distance swam
$\left(\mathrm{F}_{4,39}=10.72, \mathrm{P}>0.05\right.$; Figure 3B $)$ between control and $\mathrm{NaHS}(100 \mu \mathrm{mol} / \mathrm{kg} / \mathrm{d})$-treated alone groups.

In the probe trial, the platform was removed and the rats were placed into the opposite quadrant and allowed to swim freely for $120 \mathrm{~s}$. STZ-induced diabetic rats showed impaired memory, as evidence by their significant decreases in the number of times crossing target quadrant $\left(\mathrm{F}_{4,38}=8.65, \mathrm{P}<0.001\right.$; Figure $\left.3 \mathrm{C}\right)$ and the duration spent on target quadrant compared with the blank group. (F4, 42=4.4, $\mathrm{P}<0.01$; Figure 3D). However, NaHS significantly enhanced the duration that the diabetic rats spent on the target quadrant (Figure 3C) and the frequencies that the diabetic rats crossed the target quadrant (Figure 3D) compared to the STZ-treated alone
A
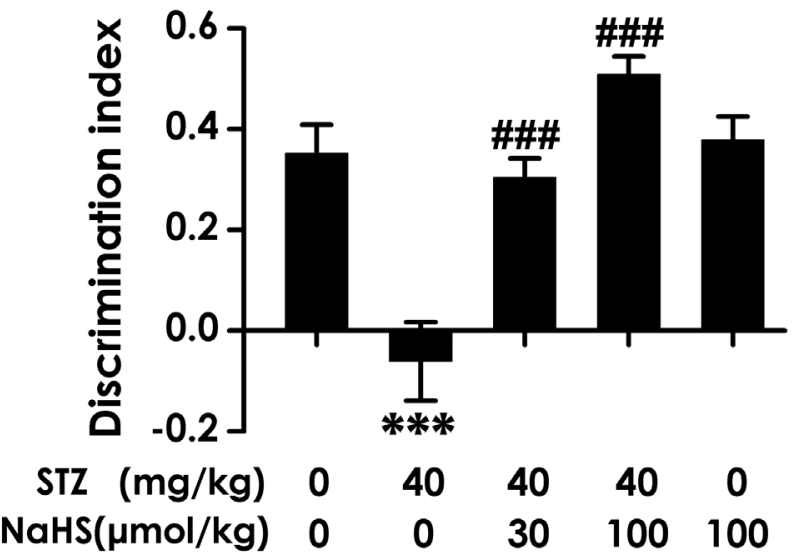

B

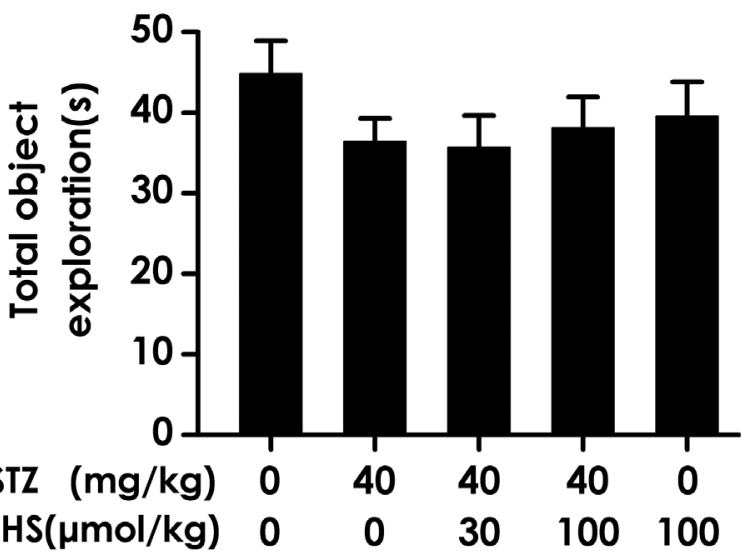

Figure 1: Effect of NaHS on the cognitive decline of STZ-induced diabetic rats in Novel object recognition (NOR) test. Rats were once injected with STZ (40 mg/kg) and treated with NaHS (30 and $100 \mu \mathrm{mol} / \mathrm{kg} / \mathrm{d}$, ip) for 30 days. The cognitive performance of rats was test using the NOR task and the discrimination index (A) and total object exploration (B) were recorded. The data are expressed as mean \pm S.E.M. ( $\mathrm{n}=7-12$ per group). ${ }^{* * *} P<0.001$, versus control group; ${ }^{\# \# ~} P<0.001$, versus STZ-treated alone group.

A

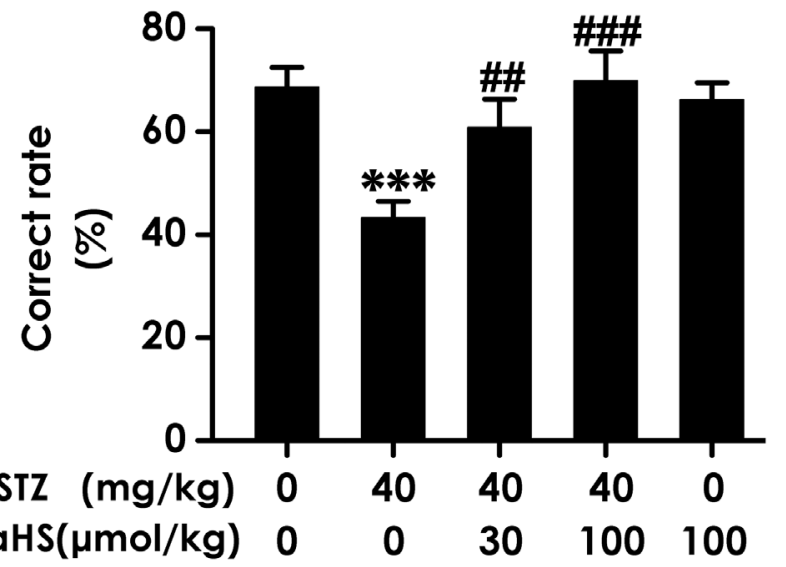

B

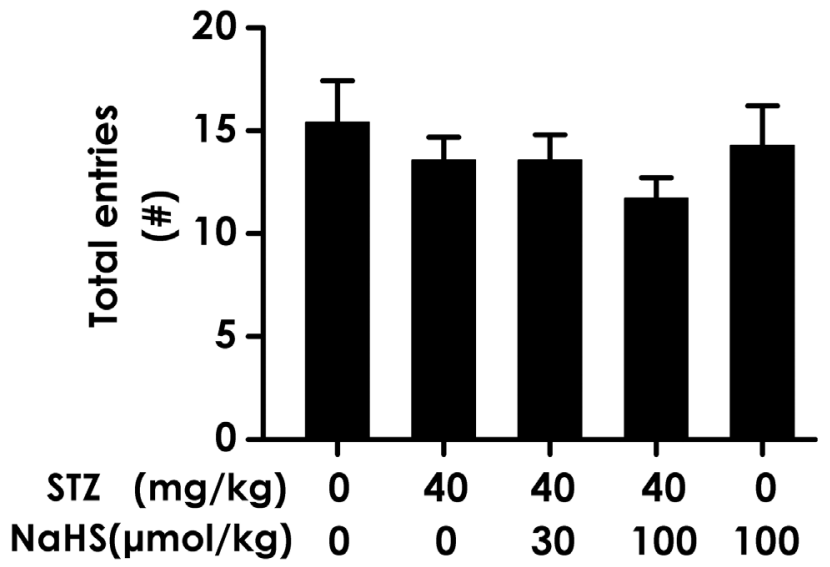

Figure 2: Effect of NaHS on the working memory dysfunction of STZ-induced diabetic rats in Y-maze test. Rats were once injected with STZ (40 mg/kg) and treated with NaHS (30 and $100 \mu \mathrm{mol} / \mathrm{kg} / \mathrm{d}$, ip) for 30 days. The cognitive performance of rats was test using the Y-maze task and the correct rate (A) and total entries number (B) were recorded. The data are expressed as mean \pm S.E.M. $(\mathrm{n}=$ 7-12 per group). $* * * P<0.001$, versus control group; ${ }^{*} P<0.01,{ }^{\# \#} P<0.001$, versus STZ-treated alone group. 
group. NaHS (100 $\mu \mathrm{mol} / \mathrm{kg} / \mathrm{d}$, i.p.) alone-treated rats did not show change in this indicators. (Figure 3C, 3D). Taken together, these data suggested that NaHS apparently improved spatial learning and memory that had declined in STZ-induced diabetic rats.

\section{NaHS improves working memory of diabetic rats in Morris water maze test}

We tested working memory in the transfer phase of the hidden platform version of the water maze. STZ-induced diabetic rats exhibited significant higher escape latency (F4, 40=30.37, $\mathrm{P}<0.001$; Figure 4A) and a significant enhancement during the swimming distance (F4, 39=10.7, $\mathrm{P}<0.001$; Figure 4B) in finding the hidden platform on day 1, 2, 3 and 4 during training trials compared to control group rats, implying a significant impairment of working memory process. However, treatment with NaHS significantly decreased the escape latency (Figure 4A) and the swimming distance (Figure 4B) of STZ-induced diabetic rats compared to STZ-treated alone group during $4 \mathrm{~d}$ training. There were no differences of the escape latency (Figure 4A) and the swimming distance (Figure 4B) between control and
NaHS $(100 \mu \mathrm{mol} / \mathrm{kg} / \mathrm{d})$-treated alone groups. Similarly, in the transfer phase of the probe trial of the water maze, an obvious decreases emerged on STZ-induced diabetic rats in the number of times crossing target quadrant (F4, $35=5.81, \mathrm{P}<0.001$; Figure $4 \mathrm{C}$ ) and the duration spent on target quadrant (F4, 35=4.89, $\mathrm{P}<0.01$; Figure 4D) However, treatment with NaHS significantly increased the number of times that the diabetic rats crossed the target quadrant (Figure 4C) and the duration that the diabetic rats spent on the target quadrant (Figure 4D) compared to STZ-treated alone group. NaHS $(100 \mu \mathrm{mol} / \mathrm{kg} / \mathrm{d}$, i.p. $)$ did not alter the number of times crossing target quadrant (Figure 4C) and the time spent on target quadrant (Figure 4D) when no STZ was applied. Taken together, these data suggested that NaHS apparently improved working memory that had declined in STZ-exposed diabetic rats.

\section{Rules out the influences by the changes of vision and motor ability on learning and memory in the rats}

In order to avert the possibility that the above results are derived from the alterations of vision and motor ability

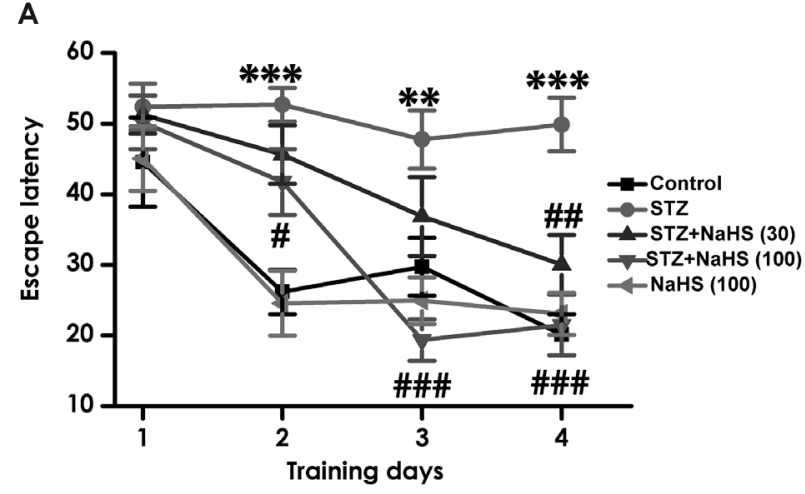

B

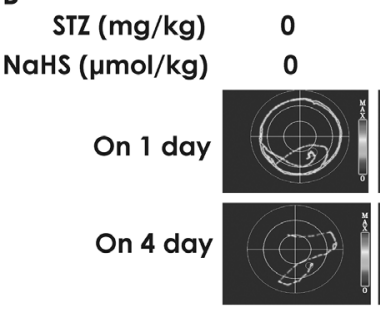

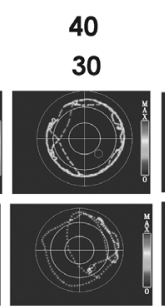

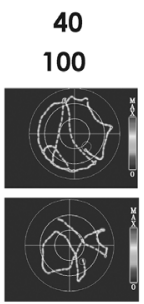

c

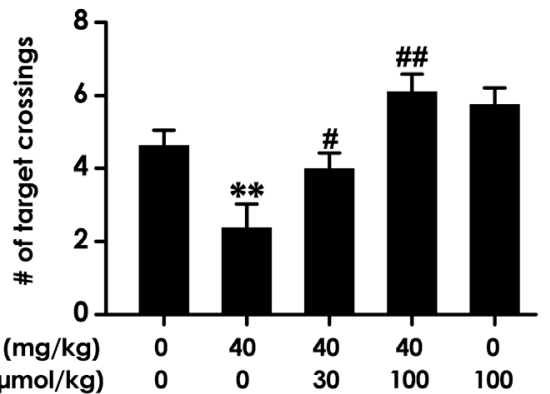

D

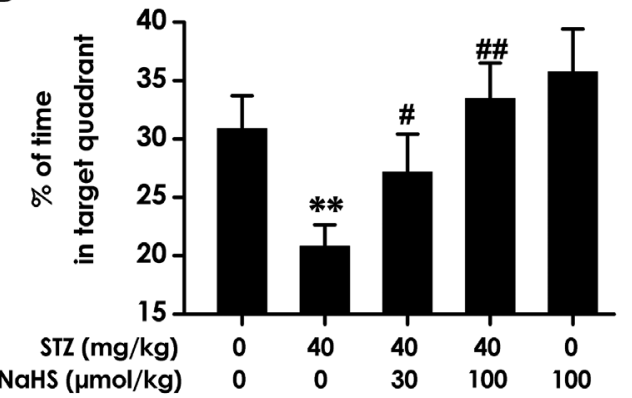

Figure 3: Effects of NaHS on the spatial learning and memory dysfunction of STZ-induced diabetic rats in the acquisition and probe phase of Morris water maze test. Rats were once injected with STZ (40 mg/kg) and treated with $\mathrm{NaHS}$ (30 and $100 \mu \mathrm{mol} / \mathrm{kg} / \mathrm{d}$, ip) for 30 days. The cognitive performance of rats was test using the Morris water maze task. (A) Acquisition profiles: rats were submitted to acquisition of an invisible platform placed in a fixed location (target quadrant) with four swims per day during 4 days. (B) Representative swimming tracks of rats searching for the underwater platform at $1^{\text {st }}$ and $4^{\text {th }}$ training day. (C, D) One day after finishing the place navigation task (day 5), the platform was removed and the rats were submitted to the probe trial, and the percentage of time spent in the target quadrant $(\mathbf{C})$ and the number of times that the animal crossed the target quadrant platform area (D) were analyzed. The data are expressed as the mean \pm S.E.M. $(\mathrm{n}=7-12) .{ }^{* *} P<0.01$, ${ }^{* * *} p<0.001$, versus control group; ${ }^{\#} P<0.05,{ }^{\#} P<0.01,{ }^{\# \#} P<0.001$, versus STZ-treated alone group. 
in the rats, we measured the escape latency and the average swimming speed by performing a visible platform test. There was no difference in the escape latencies $\left(\mathrm{F}_{4,45}=0.946\right.$, $\mathrm{P}>0.05$; Figure 5A) and swimming speed (F4, $32=0.397$, $\mathrm{P}>0.05$; Figure $5 \mathrm{~B}$ ) among all rats, which indicated the change of all indexes in the these experiments are not due to alterations or difference in visual performance or athletic ability of each groups of rats.

\section{NaHS downregulats hippocampal GRP78 expression in STZ-induced diabetic rats}

An important physiological role for hippocampal ER stress in cognitive impairment development was found in diabetes. [29]. This finding had raised the question of whether inhibition of hippocampal ER stress is existed in
$\mathrm{H}_{2} \mathrm{~S}$ on the improvement of cognitive function in diabetic rats. To investigate this, we quantified multiple parameters, firstly measure the expression of GRP78, which is a pivotal marker of ER stress. As schematized in Figure 6, hippocampal GRP78 expression was significantly increased in diabetic rats; however, treatment with NaHS clearly decreased the protein expression of hippocampal GRP78 in diabetic rats, indicating the response of diabetes to hippocampal ER stress and the suppressive function of NaHS on STZ-induced hippocampal ER stress.

\section{NaHS represses hippocampal CHOP expression in $\mathrm{STZ}$-induced diabetic rats}

To further ascertain whether $\mathrm{H}_{2} \mathrm{~S}$ inhibits hippocampal ER stress, we provide another result that hippocampal
A

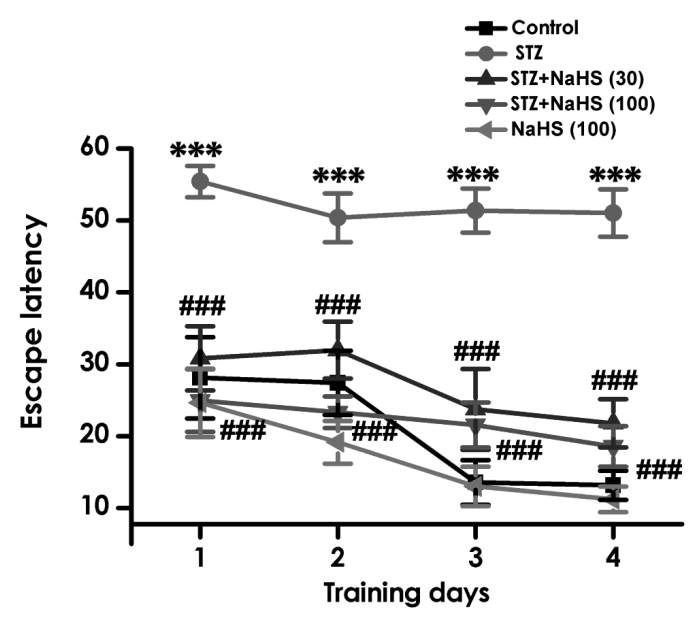

C

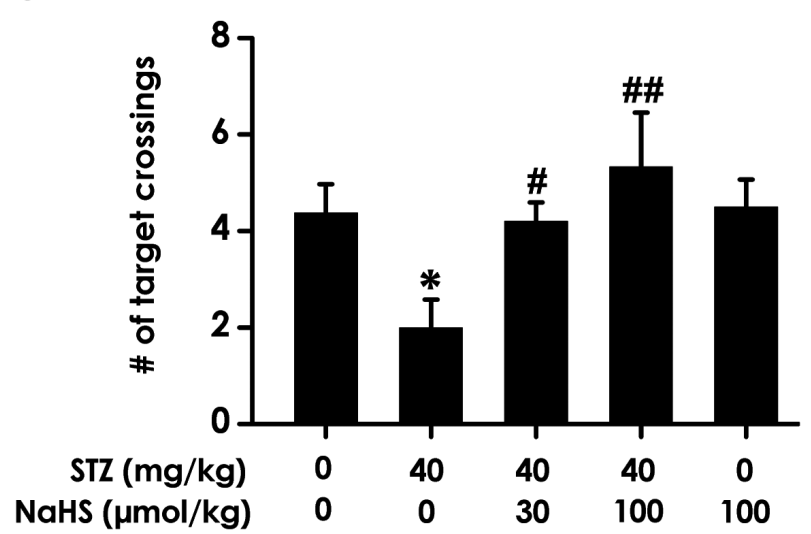

B

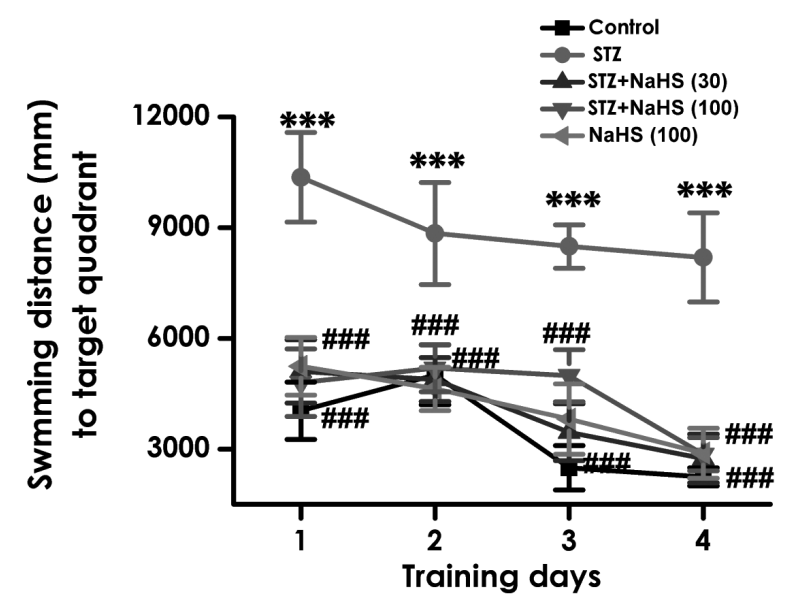

D

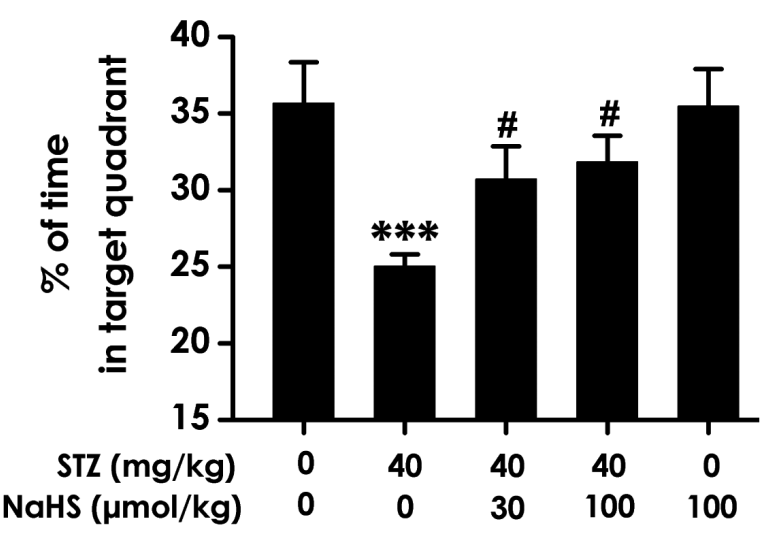

Figure 4: Effect of NaHS on the working memory dysfunction of STZ-induced diabetic rats in the transfer acquisition and probe phases of Morris water maze test. (A, B) After the visible platform test, the rats were submitted to the transfer acquisition phase of Morris water maze test for four consecutive days, and the latency traveled to find the hidden platform (A) and the distance swam in searching for the hidden platform (B) in the transfer acquisition phase were recorded. (C, D) After the transfer acquisition phase of Morris water maze test, the rats were submitted to the transfer probe phases of Morris water maze test, and the number of times that the animal crossed the target quadrant platform area (C) and the percentage of time spent in the target quadrant (D) were analyzed. The data are expressed as the mean \pm S.E.M. $(\mathrm{n}=7-12)$. ${ }^{*} P<0.05$, ${ }^{* * *} P<0.001$, versus control group; ${ }^{\#} P<0.05,{ }^{\# \#} P<0.01,{ }^{\# \#} P<0.001$, versus the STZ-treated alone group. 
CHOP protein level, which is associated with ER Stress. The expression of this important protein was clearly increased in the hippocampus of STZ-exposed diabetic rats; in contrast, the boost of hippocampal CHOP expression in diabetic rats was reduced by means of NaHS (Figure 7). These findings have identified a function of suppression of ER stress by NaHS in hippocampus of STZ-exerted rats.

\section{NaHS reduces hippocampal cleaved caspase-12 expression in STZ-induced diabetic rats}

Cleaved caspase-12 is a crucial mediator of apoptosis induced by ER stress. Thus, we turned our attention to cleaved caspase-12. As schematized in Figure 8, hippocampal cleaved caspase-12 was significantly upregulated in STZ-induced diabetic rats; however, treatment with NaHS clearly suppressed the upregulation. This was further supported that a physiological role for NaHS treatment in protect against STZ-induced hippocampal ER stress.

\section{NaHS enhances the generation of hippocampal endogenous $\mathrm{H}_{2} \mathrm{~S}$ in STZ-exposed diabetic rats}

To broaden our understanding of the improvement of cognitive impairment as well as the role of NaHS, we identifies whether the generation of hippocampal endogenous $\mathrm{H}_{2} \mathrm{~S}$ in STZ-induced diabetic rats is decrease and whether NaHS reverse this decrease, we performed sensitive sulphur electrode to measure generation of hippocampal $\mathrm{H}_{2} \mathrm{~S}$. As schematized in Figure 9, hippocampal endogenous $\mathrm{H}_{2} \mathrm{~S}$ generation in $\mathrm{STZ}$-induced diabetic rats was significantly decreased compared to blank group. However, NaHS evidently prevented the decreased of hippocampal $\mathrm{H}_{2} \mathrm{~S}$ generation in diabetic rats. These data show the important role played by
NaHS in improve diabetic cognitive impairment induced by ER stress was rely on enhances the generation of hippocampal $\mathrm{H}_{2} \mathrm{~S}$.

\section{DISCUSSION}

It has been demonstrated that the protective effect of $\mathrm{H}_{2} \mathrm{~S}$ against the learning and memory decline in experimental $\mathrm{AD}[16,17]$. The metabolic disorder of diabetes is known to associated with the damage of central nervous system (CNS), which is often believed to contribute to changes in neurotransmission and structural malignant transformation, even interferences of learning and memory [33, 34]. In our experiments, we investigated the effects of $\mathrm{H}_{2} \mathrm{~S}$ on the diabetes-associated cognitive impairment and the underlying mechanisms. We provided evidence that NaHS improves the cognitive impairments in STZ-exposed diabetic rats. In parallel to this, NaHS attenuates the hippocampal ER stress in STZ-exposed diabetic rats. NaHS is now regard as a $\mathrm{H}_{2} \mathrm{~S}$ donor in the current research, which generates $\mathrm{H}_{2} \mathrm{~S}$ through direct interaction of dissociated HS- and $\mathrm{H}+$ in solution. [35, 36]. $\mathrm{H}_{2} \mathrm{~S}$ is known as a toxic gas and its toxicity associated with concentration. $\mathrm{H}_{2} \mathrm{~S}$ can be generated in the brain and the endogenous $\mathrm{H}_{2} \mathrm{~S}$ under physiological conditions in the brain is a relatively high concentration at $50-160 \mu \mathrm{mol} / \mathrm{L}$ [37]. The concentration of $\mathrm{H}_{2} \mathrm{~S}$ induced by NaHS in the present work is close to its physiological concentration. NaHS at $100 \mu \mathrm{mol} / \mathrm{kg} / \mathrm{d}$ did not alter the cognitive function, which indicated $\mathrm{NaHS}$ in the present work has no toxicity to rats. Therefore, our results for the first revealed that $\mathrm{H}_{2} \mathrm{~S}$ is an important protective factor against cognitive dysfunction in $\mathrm{DM}$ and the underlying mechanism is involved in prevention of ER stress in the hippocampus.

The MWM test has been identified as a mode to assess rodentine spatial learning and memory, which get
A

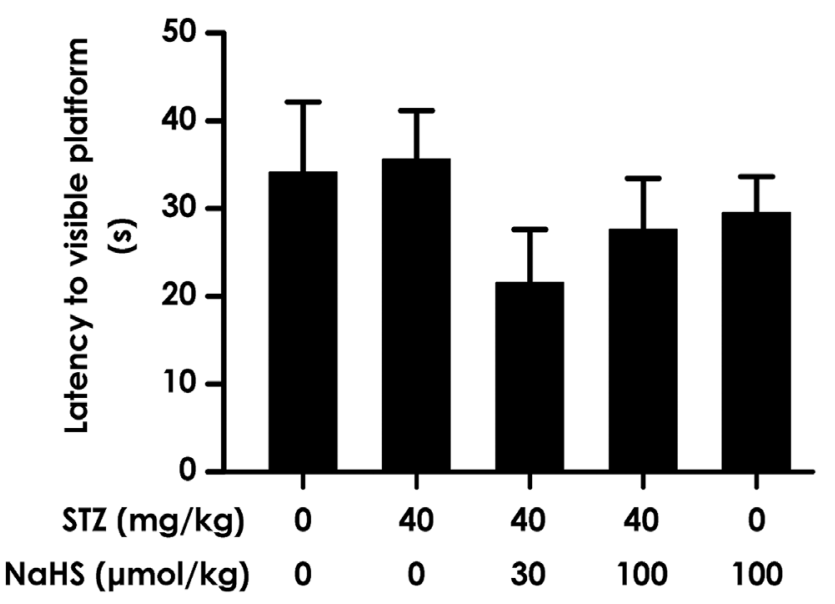

B

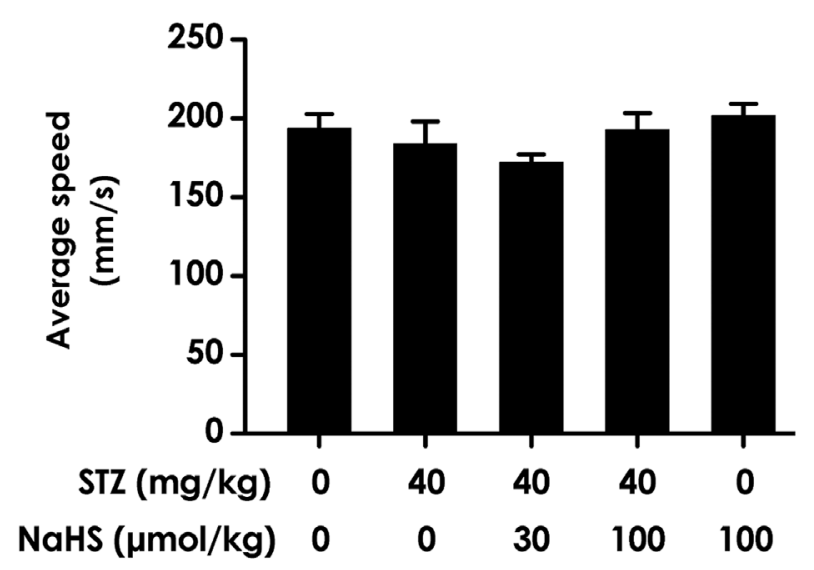

Figure 5: The escape latency and average swimming speed in the visible platform test. After the transfer probe test, the rats were submitted to the visible platform test and the latency to reach the platform (A) and the average swimming speed of rats (B) were recorded. 


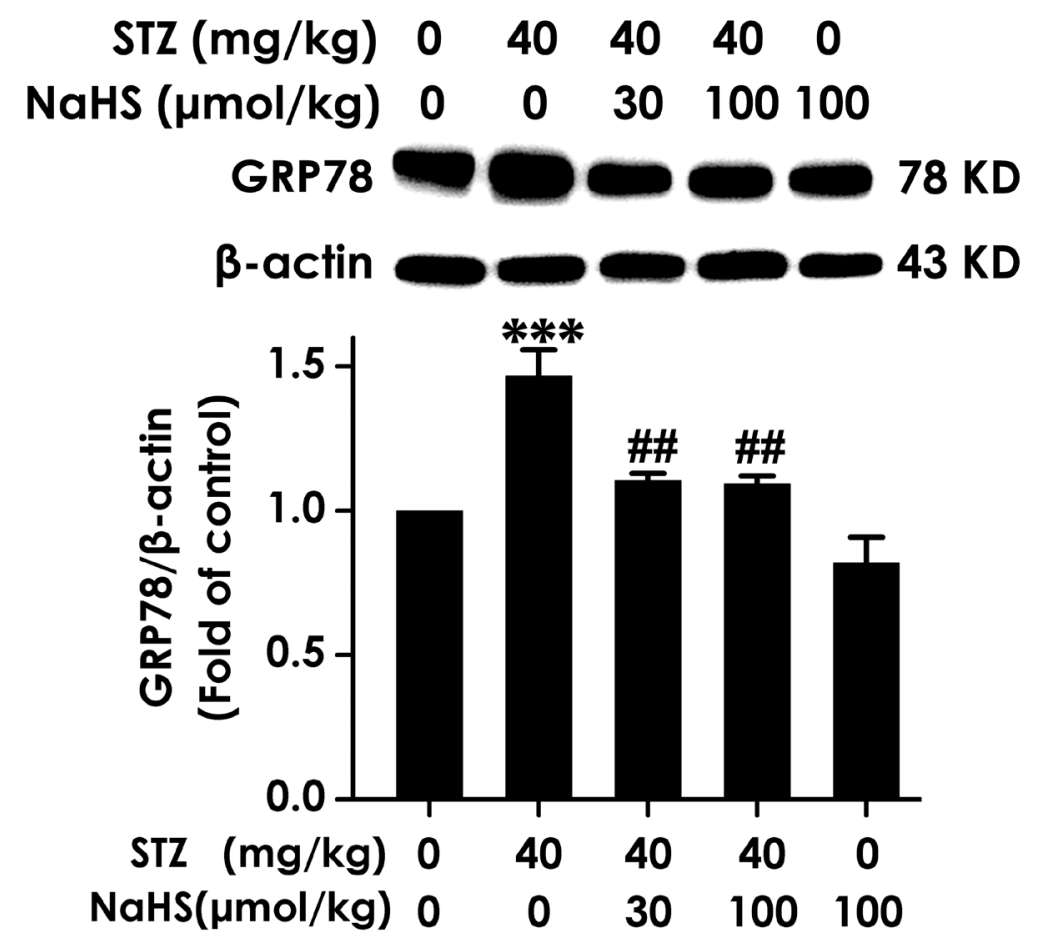

Figure 6: Effect of NaHS on the expression of GRP78 in the hippocampus of STZ-induced diabetic rats. Rats were once injected with STZ (40 mg/kg) and treated with NaHS (30 and $100 \mu \mathrm{mol} / \mathrm{kg} / \mathrm{d}$, ip) for 30 days. The expression of GRP78 in the hippocampus of rats was detected by Western blot using anti-GRP7 8 antibody and $\beta$-actin was used as a loading control. Values are expressed as the mean \pm S.E.M. (n=3-5). ${ }^{* * *} P<0.001$, versus control group; ${ }^{\#} P<0.01$, versus $\mathrm{STZ}$-treated alone group.

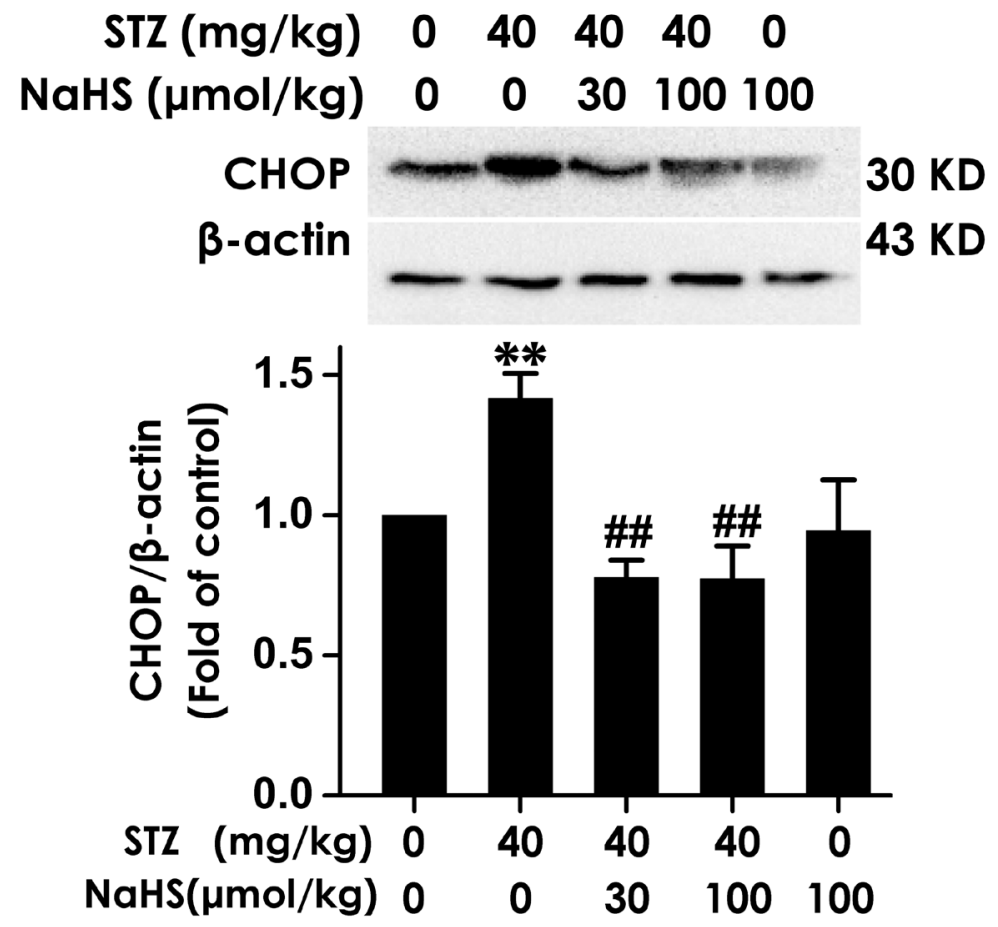

Figure 7: Effect of NaHS on the expression of CHOP in the hippocampus of STZ-induced diabetic rats. Rats were once injected with STZ (40 mg/kg) and treated with NaHS (30 and $100 \mu \mathrm{mol} / \mathrm{kg} / \mathrm{d}$, ip) for 30 days. The expression of CHOP in the hippocampus of rats was detected by Western blot using an anti-CHOP antibody and $\beta$-actin was used as a loading control. Values are expressed as the mean \pm S.E.M. $(\mathrm{n}=3-5)$. ${ }^{* *} P<0.01$, versus control group; ${ }^{\#} P<0.01$, versus $\mathrm{STZ}$-treated alone group. 
wide spread acceptance [38]. In MWM, the spatial learning of rats is evaluated through the hidden-platform acquisition test and the spatial memory is investigated in the probe trial test. We showed that STZ-induced diabetic rats exhibited an increase in the escape latency in training session, and decreases in the crossing platform times and the percentage of time spent on the target quadrant when implemented probe trail, which indicated STZ-exposed diabetic rats have the descendant of spatial learning and memory. Of important, NaHS-treated diabetic rats showed that the escape latency and the journey in the goal quadrant were markedly decreased and that the duration spent on the goal quadrant as well as the time of crossings of the area of goal were markedly enhanced. Further, the visible platform test supported the conclusion by ruling out change in animal swimming ability and vision that may also influence spatial learning and memory. Thus, it was reasonable to believe that $\mathrm{H}_{2} \mathrm{~S}$ could improve the spatial learning and memory performance in the diabetic rats.

In addition, we tested the working memory functions of rats in the transfer phase of the hidden platform version of the MWM. In this experiment, we transferred the platform to the contrary quadrant, and their capacity for learning and remembering the new platform location were measured. STZ-induced diabetic rats had difficulty in forming a good working memory of the new platform location, as evident by that they exhibited significant higher escape latency and a significant increase in the swim journey to find the hidden platform during 4-d training trials compared to control group rats and explored the new training quadrant and crossed the platform location significantly less often than did the control rats in a probe trial 1 day after the end of training. Taken together, results of the escape latency, travelled distance in the goal quadrant, duration spent on quadrant, and times of platform crossings indicated that $\mathrm{H} 2 \mathrm{~S}$ improves the working memory performance in STZ-induced diabetic rats. The Y-maze task is a specific and sensitive test for working memory in a new environment $[39,40]$. In the Y-maze test, we found that administration of $\mathrm{H}_{2} \mathrm{~S}$ led to a marked increasing in correct rate in diabetic rats. This result also indicates the potential role of $\mathrm{H} 2 \mathrm{~S}$ to improve the STZexposed diabetic working memory disorder.

The NOR test on the basis of the differential exploration of familiar and new objects [41], and it is used to study short-term, declarative memory and attention. In the present study, we showed that in NOR, rats treated with

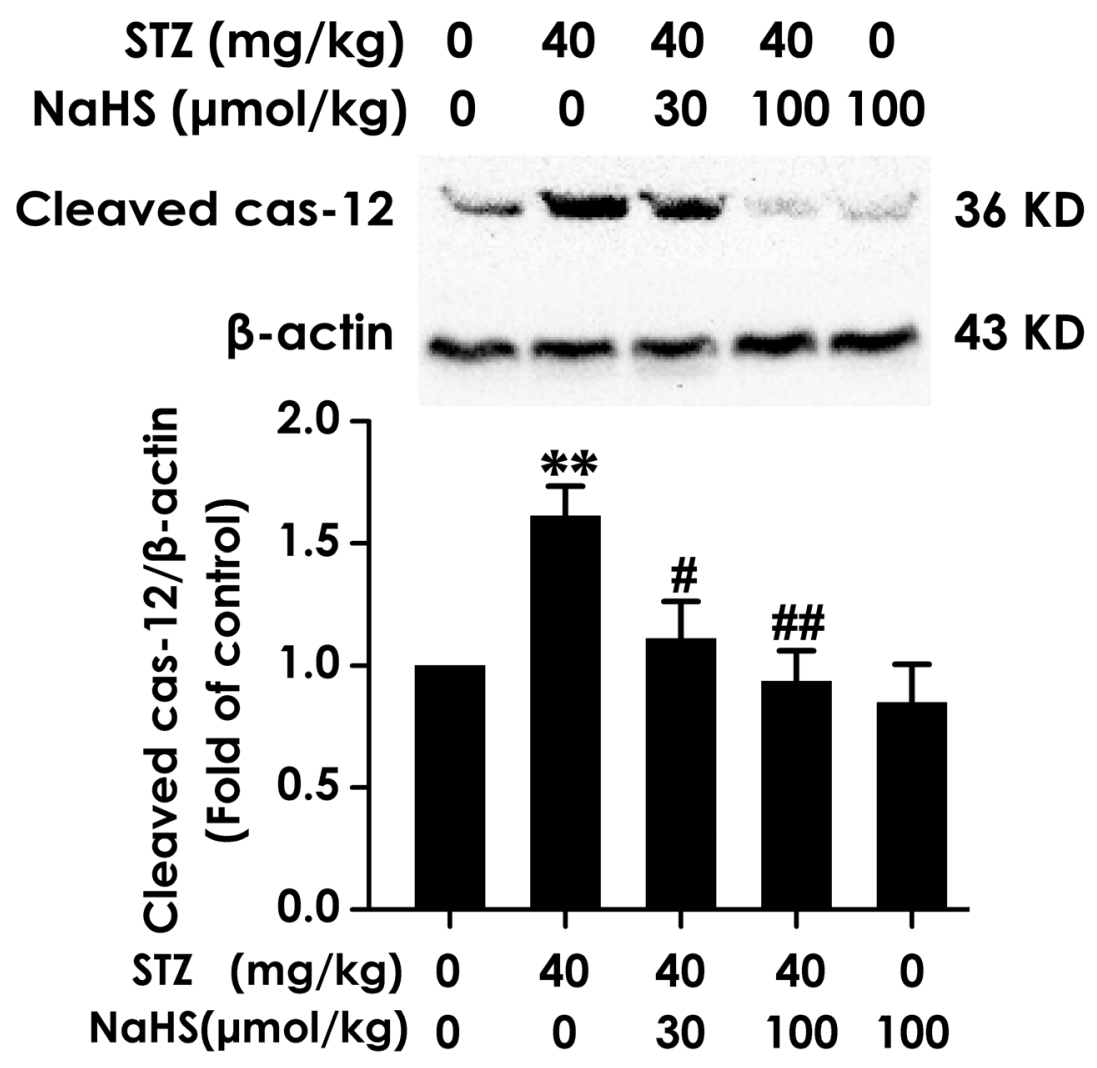

Figure 8: Effect of NaHS on the expression of cleaved caspase-12 in the hippocampus of STZ-induced diabetic rats. Rats were once injected with STZ (40 mg/kg) and treated with NaHS (30 and $100 \mu \mathrm{mol} / \mathrm{kg} / \mathrm{d}$, ip) for 30 days. The expression of cleaved caspase-12 in the hippocampus of rats was detected by Western blot using an anti-cleaved caspase-12 antibody and $\beta$-actin was used as a loading control. Values are expressed as the mean \pm S.E.M. $(\mathrm{n}=3-5) .{ }^{* *} P<0.01$, versus control group; ${ }^{\#} P<0.05$, ${ }^{\# \#} P<0.01$, versus STZtreated alone group. 
STZ displayed a decreased discrimination index, which also indicates the cognitive dysfunction. Furthermore, the protective action of $\mathrm{H}_{2} \mathrm{~S}$ in diabetic cognitive dysfunction was further supported in novel object recognition test. Administration of $\mathrm{H}_{2} \mathrm{~S}$ dose dependently upregulated the discrimination index of diabetic rats in the novel object recognition test.

ER stress is often believed to have a great importance in the induction of insulin resistance and diabetes $[25,42,43]$. The importance of the hippocampus for cognitive functions is well established [44, 45]. Especially, spatial memory strongly based on activity of hippocampus min rats is widely accepted [46]. When cells were exposed to stress or damage, ER stress is a early or initial cellular response, which is associated with neuronal death in many neurodegenerative diseases. [47]. ER stress-induced apoptosis in the hippocampus is assessed to clarify the mechanism of diabetic cognitive impairment [29]. Therefore, we speculated that $\mathrm{H}_{2} \mathrm{~S}$ has function as efficient anti-cognitive disorder by alleviating hippocampal ER stress. Our experiments showed that the hippocampal expressions of GRP78, CHOP, and cleaved caspase-12 in diabetic rats were all increased. In consistent with the previous report [29], our data also suggested that hippocampal ER stress is often believed to contributes to the diabetic cognitive dysfunction. It is to be noted that administration of $\mathrm{H}_{2} \mathrm{~S}$ significantly inhibited the expressions of above proteins in the hippocampus

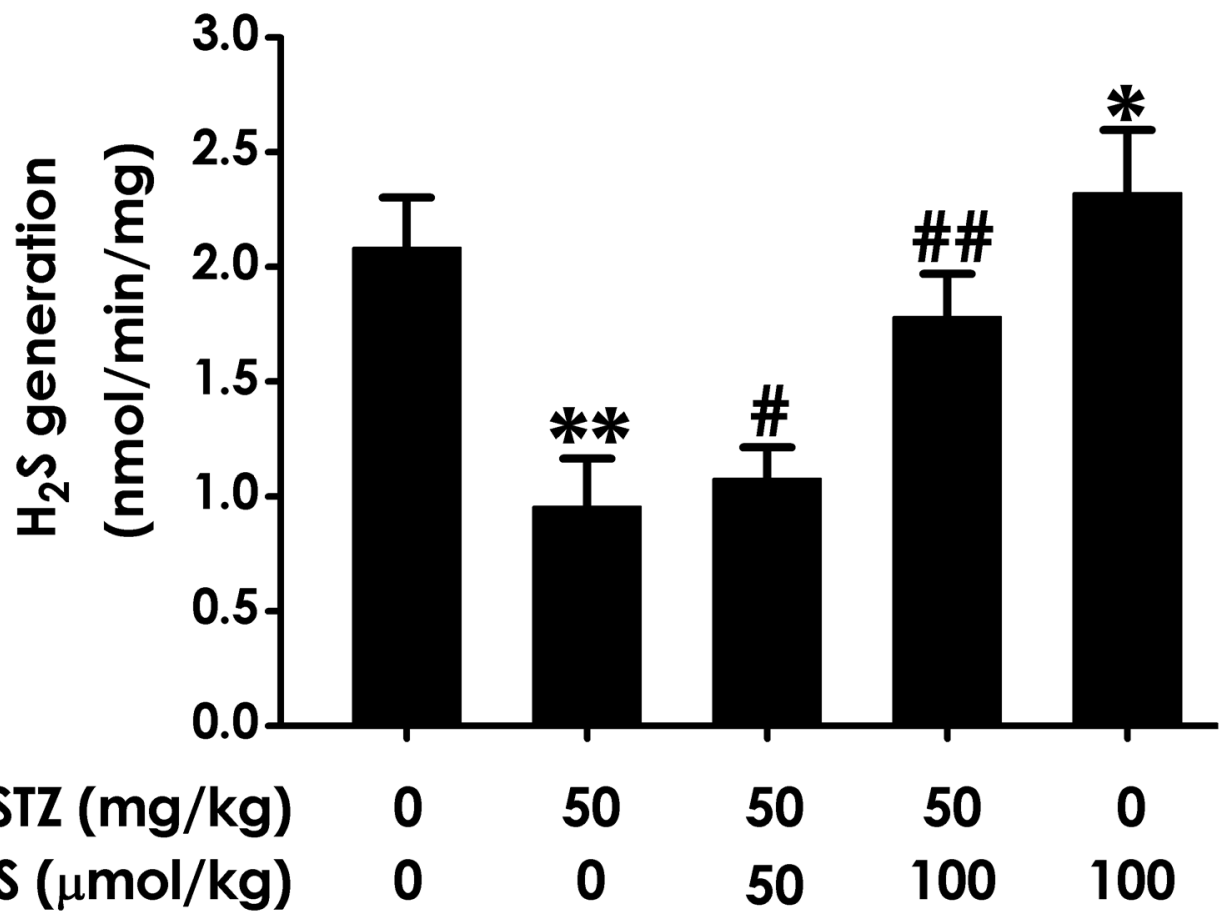

Figure 9: Effect of NaHS on the generation of hippocampal H2S in STZ-induced diabetic rats. Rats were once injected with STZ (40 mg/kg) and treated with NaHS (30 and $100 \mu \mathrm{mol} / \mathrm{kg} / \mathrm{d}$, ip) for 30 days. The generation of hippocampal of rats was assayed by sensitive sulphur electrode. Values are expressed as the mean \pm S.E.M. $(\mathrm{n}=3-5) .{ }^{*} P<0.05,{ }^{* *} P<0.01$, versus control group; ${ }^{*} P<0.05$, ${ }^{\#} P<0.01$, versus STZ-treated alone group.

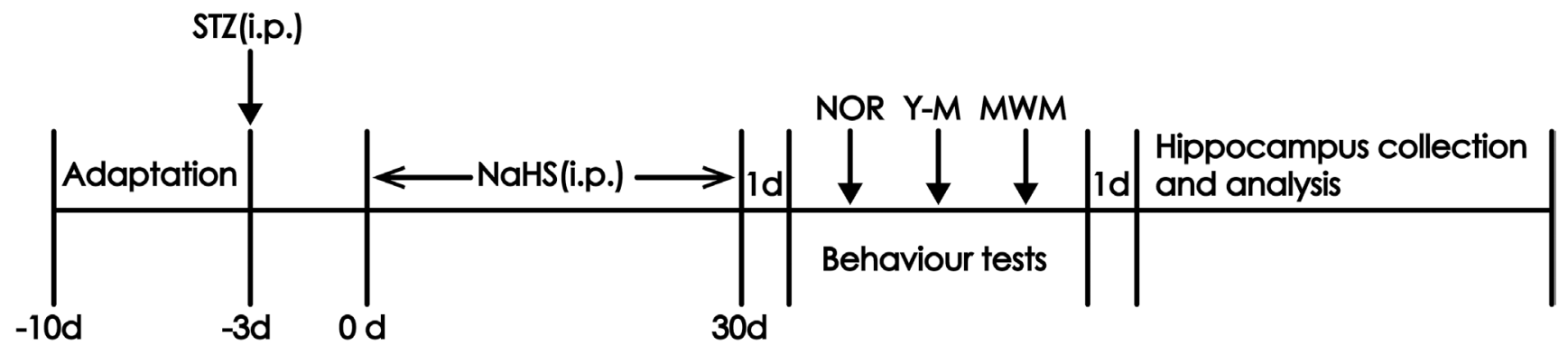

Figure 10: Schematic diagram of the experimental schedule. NOR, novel objects recognition test; Y-M, Y-maze test; MWM, Morris water maze test. 
of STZ-induced diabetic rats. These results suggested that $\mathrm{H}_{2} \mathrm{~S}$ have physiological role in downregulating the elevated ER stress in the hippocampus of diabetic rats. Our recent data also demonstrated that $\mathrm{H}_{2} \mathrm{~S}$ protect $\mathrm{PC} 12$ cells from formaldehyde exposed ER stress [48]. These published findings was further explained and supported our present results. Thus, the present work revealed that $\mathrm{H} 2 \mathrm{~S}$ improves the diabetic cognitive dysfunction through inhibiting the hippocampal ER stress. It is interesting to note an opposite finding that $\mathrm{H}_{2} \mathrm{~S}$ increases ER stress in Beta cells in vitro [49]. The difference in observed model, pancreatic beta cells in vitro and hippocampus tissues in vivo, may account for the discrepancy between the two studies. In order to further demonstrated that improving the diabetic cognitive impairment by suppressing ER stress indeed depend on the increase in hippocampal endogenous $\mathrm{H}_{2} \mathrm{~S}$, we investigated whether NaHS treatment changes the hippocampal endogenous $\mathrm{H}_{2} \mathrm{~S}$ generation in STZ-induced diabetic rats. The hippocampal endogenous $\mathrm{H}_{2} \mathrm{~S}$ generation of diabetic rats is decrease, while this downregulation is reversed by intraperitoneal NaHS. Therefore, we suggested that NaHS-provided protection in diabetic rats depend on the increase in the hippocampal endogenous $\mathrm{H}_{2} \mathrm{~S}$ generation. However, it has been reports that $\mathrm{H}_{2} \mathrm{~S}$ formation in pancreas and liver was markedly increased in STZ-induced diabetic rats [50]. This conflict is probably due to the discrepancy of organs.

In conclusion, our results clearly indicated that diabetes mellitus triggers neurocognitive decline in adult rats and $\mathrm{H}_{2} \mathrm{~S}$ prevents this neurofunctional impairment as demonstrated by the MWM, the Y-maze, and the novel object recognition tests. We also showed that $\mathrm{H}_{2} \mathrm{~S}$ attenuates the ER stress in the hippocampus of diabetic rats. These finding implied the inhibition of hippocampal ER stress is involved in $\mathrm{H}_{2} \mathrm{~S}$-enhanced the cognitive function in diabetic rats. Our findings suggested that $\mathrm{H}_{2} \mathrm{~S}$ is a possible candidate for the prevention and treatment of cognitive dysfunction in diabetes mellitus. However, the further mechanisms of this protective action of $\mathrm{H}_{2} \mathrm{~S}$ in diabetic cognitive impairment will be in depth explored in our future work. Furthermore, we will carry out this experiment in clinically relevant model progressively.

\section{MATERIALS AND METHODS}

\section{Drugs}

$\mathrm{NaHS}$ (dissolved in nonpyrogenic $0.9 \% \mathrm{NaCl}$ and filtered through a $0.2 \mu \mathrm{m}$ filter) was obtained from SigmaAldrich (St Louis Missouri, USA). Streptozotocin (STZ) was purchased from MP Biomedicals, LLc (Santa Ana, California, USA). Specific monoclonal anti-GRP78 and anti-CHOP antibodies were purchased from Epitomic Inc (Burlingame, UK). Specific monoclonal anti-cleaved caspase-12 antibody was obtained from Sigma Chemical (St Louis, MO, USA).

\section{Animals and treatments}

Adult male Sprague-Dawley rats (280-300g), obtained from the SJA Lab Animal Center of Changsha (Changsha, China). Rats were given free access to food and water, and kept on a $12 \mathrm{~h}$ light/dark cycle (lights on 08:30-20:30) and under constant temperature $\left(23 \pm 1^{\circ} \mathrm{C}\right)$ and humidity (60\%). After one week of acclimatization to the laboratory conditions, rats were randomly divided into five groups: Control group, received daily intraperitoneal (i.p.) infusions of normal saline; STZ-treated alone group, received a single intraperitoneal infusion of STZ $(40 \mathrm{mg} /$ $\mathrm{kg}$ ) and 30-d infusions of normal saline (i.p.); the cotreated with STZ and $30 \mu \mathrm{mol} / \mathrm{kg} / \mathrm{d}$ NaHS group, received a single intraperitoneal infusion of STZ $(40 \mathrm{mg} / \mathrm{kg})$ and $30-\mathrm{d}$ infusion of NaHS $(30 \mu \mathrm{mol} / \mathrm{kg} / \mathrm{d}$, ip); the co-treated with STZ and $100 \mu \mathrm{mol} / \mathrm{kg} / \mathrm{d}$ NaHS group, received a single intraperitoneal infusion of STZ (40 mg/ $\mathrm{kg}$ ) and 30-d infusion of NaHS $(100 \mu \mathrm{mol} / \mathrm{kg} / \mathrm{d}$, ip); and $100 \mu \mathrm{mol} / \mathrm{kg} / \mathrm{d}$ NaHS (i.p.)-treated alone group, received an intraperitoneal infusion of NaHS $(100 \mu \mathrm{mol} / \mathrm{kg} / \mathrm{d})$ for $30 \mathrm{~d}$. After diabetic rat model was established, we injected NaHS. Behavioral tests that assess cognitive ability were performed $24 \mathrm{~h}$ after the last injection of NaHS. The experiments were always conducted between 9:00 and 17:00 h, which were carried out in accordance with the National Institutes of Health Guide for the Care and Use of Laboratory Animals and were approved by the Animal Use and Protection Committee of University of South China. All efforts were made to minimize the number of animals used and their suffering. Within one day after the behavioral tests, animals were killed and the hippocampus region tissues of the brain were rapidly removed on the ice-cold artificial cerebrospinal fluid and stored at $-80^{\circ} \mathrm{C}$ for analysis (Figure 10).

\section{Experimental induction of diabetes}

Diabetes was induced in rats by using an earlier reported method [51]. In brief, STZ was dissolved in 0.1 $\mathrm{M}$ sodium citrate buffer, $\mathrm{pH} 4.4$ and administered at the dose of $40 \mathrm{mg} / \mathrm{kg}$ through i.p. route. STZ-treated rats received $5 \%$ of glucose solution instead of water for 24 $\mathrm{h}$ after injection of STZ in order to reduce death due to hypoglycemic shock. Blood samples were taken from the tail vein $72 \mathrm{~h}$ after STZ injection to measure blood glucose levels. Only animals with fasting blood glucose levels over $16.7 \mathrm{mmol} / \mathrm{L}$ were considered diabetic and used for the further study [2].

\section{Novel object recognition test}

The novel object recognition test was performed according to the method described previously $[52,53]$, in order to assess the ability of rats to recognize a novel object in a familiar environment. We performed a novel object recognition test for 3 days including a habituation phase (10 min for one day), a training phase (5 min for one day) 
and a test phase (5 min for one day) in each rat. During the habituation phase, rats were placed into an open-field apparatus consisting of a rectangular area $(50 \mathrm{~cm}$ wide $\times$ $50 \mathrm{~cm}$ long $\times 40 \mathrm{~cm}$ high) allowed to adapt for $10 \mathrm{~min}$ for each mouse without objects. Then, during the training phase, two identical objects were presented to each rat for $5 \mathrm{~min}$. Twenty-four hours after the training phase, one of the old objects was replaced with a novel object and presented to each rat for 5 min during the test phase. Object exploration time was recorded using a video-assisted tracking system. The cognitive function of rats is measured by the discrimination index [= (novel object exploration time - familial object exploration time)/total exploration time $\times 100 \%$ ]. To control the odor cues, the open field arena and the objects were thoroughly cleaned with alcohol, dried and ventilated for a few minutes between rats.

\section{Y- maze test}

As described previously [52, 54], Y-maze $(90 \mathrm{~cm}$ long $\times 90 \mathrm{~cm}$ wide $\times 76 \mathrm{~cm}$ high) was made of blackcolored acryl and consists of three arms (A, B and C) at $120^{\circ}$ angles to each other. Rats were habituated in the $\mathrm{Y}$ maze recording room for $30 \mathrm{~min}$. During the habituation phase, rats were placed into the intersection of three arms and allowed to move freely $2 \mathrm{~min}$. And then, rats were replaced in the intersection of three arms and allowed to move freely through the maze and to enter as many arms as they like during the 5-min sessions of test phase. Arm entry sessions were recorded when the hind paws of the rats were completely placed in the arm. Consecutive entry into three arms in an alternative order was defined as successive entries on overlapping triplet sets, and the correct response ratio was calculated as the ratio of overlapping triplet times/total entry times. The cognitive function of rats is measured by the correct response ratio.

\section{Morris water maze (MWM) test}

Cognitive function of rats was assessed by using Morris water maze test as described earlier [55-57]. The experimental apparatus consisted of a circular water tank (180 $\mathrm{cm}$ in diameter, $60 \mathrm{~cm}$ in height), filled with water (23 $\pm 1^{\circ} \mathrm{C}$ ) to a depth of $30 \mathrm{~cm}$, which was rendered opaque by adding milk powder. The pool was divided virtually into four equal quadrants, labeled 1-2-3-4. A colorless escape platform $(12.5 \mathrm{~cm}$ in diameter and $38 \mathrm{~cm}$ in height was placed in one of the four maze quadrants (the target quadrant) and submerged $2.0 \mathrm{~cm}$ below the water surface during acquisition trails. The platform remained in the same quadrant during the entire experiment. The pool was located in a quiet test room, surrounded by many visual cues outside of the maze which was visible from within the pool and could be used by the rats for spatial orientation. Swimming was recorded using a camera capture, and analyzed using the MT-200 Morris image motion system (Chengdu Technology and Market Corp, Chengdu, China).

\section{Acquisition trail}

During the place navigation training, each rat received four training periods per day with an intertrial interval of $60 \mathrm{~s}$ for four consecutive days. In each trial, the rat was gently placed into the pool at the middle of the circular edge in a randomly selected quadrant, with the nose pointing toward the wall and allowed a 120 -s swim to find the platform. If rats failed to find the escape platform within $120 \mathrm{~s}$ by themselves, they were placed on the platform for $20 \mathrm{~s}$ by the experimenter and their escape latency was accepted as $120 \mathrm{~s}$. After climbing onto the platform, the animal remained there for $20 \mathrm{~s}$ before the commencement of the next trial. The path and the latency to escape from the water maze (finding the submerged escape platform) were calculated for each trial.

\section{Probe trail}

On day 5 , the probe test was performed by removing platform and allowing each rat to swim freely for 120 s. The start position for each rat corresponded to one of two positions remote from the platform location in counterbalanced order. The time that rats spent in the target quadrant (where the platform was located during hidden platform training) and the number of times the rats crossed where the platform had been located were measured and calculated.

\section{Transfer acquisition trail}

One day after completion of probe trail, each rat was test in the transfer phase of the hidden platform version. In this test, the platform was moved to the opposite quadrant and rats were received four trails per day with an intertrial interval of $60 \mathrm{~s}$ for four consecutive days to learn and remember the new platform location. The path and the latency to escape from the water maze (finding the submerged escape platform) were calculated for each trial.

\section{Transfer probe trial}

One day after the end of transfer acquisition trail, the transfer probe test was performed by removing platform and allowing each rat to swim freely for $120 \mathrm{~s}$. The time that rats spent in the target quadrant (where the platform was located during the transfer phase of hidden platform training) and the number of times the rats crossed where the platform had been located were measured and calculated.

\section{Visible platform test}

After the transfer probe test, visual, motor, and motivation skills were also tested with a visible platform 
to rule out the possible deficits in sensorimotor processes. The platform was raised $2 \mathrm{~cm}$ above the water surface. The platform was moved to a novel quadrant in the pool at a fixed location for the four consisted trials. The latency to reach the platform and the average speed were recorded.

\section{Western blot analysis}

The expression of GRP78, CHOP or cleaved caspase-12 was measured by Western blot. After sacrifice, the entire hippocampus was removed and homogenized in ice-cold homogenizing buffer $(20 \mathrm{mM}$ Tris-Cl, $\mathrm{pH} 7.4$, $150 \mathrm{mM} \mathrm{NaCl}, 1 \mathrm{mM}$ EDTA, 1\% Triton X-100, $1 \mathrm{mM}$ PMSF. After centrifugation at 12,000 for $30 \mathrm{~min}$ at $4{ }^{\circ} \mathrm{C}$, the supernatant was collected and the protein content was subsequently assayed by using a BCA Protein Assay Kit (Beyotime, Shanghai, China). Equal quantities of total protein $(30 \mu \mathrm{g}$ per lane) were separated by sodium dodecyl sulfate-polyacrylamide gel electrophoresis (SDS-PAGE), followed by transfer to nitrocellulose membranes. The membranes were incubated in $5 \%$ milk at room temperature for $2 \mathrm{~h}$. Blots were then incubated with primary antibodies including rabbit monoclonal antibody for CHOP (diluted 1:1000), GRP78 (diluted 1:2000), cleaved Caspase12 (diluted 1:1000), or $\beta$-actin (1:2000). After washing with buffer, the blots were incubated in anti-rabbit secondary antibody-conjugated with horseradish peroxide (1:5000) in TBS-T with $5 \%$ milk at $4^{\circ} \mathrm{C}$ overnight. The signal of the immunoblots was visualized using an image analysis system equipped with a software BIO-ID (Vilber Lourmat, France).

\section{Sensitive sulphur electrode}

The generation of hippocampal endogenous $\mathrm{H}_{2} \mathrm{~S}$ was assayed by using sensitive Sulphur electrode as described methods previously $[58,59]$. Hippocampus region tissue (50 mg) was isolated from brain of anesthetized rats $(\mathrm{n}=3)$ and made $10 \%$ tissue homogenate in $50 \mathrm{mmol} / \mathrm{L}$ Phosphate Buffer (PH6.8). After centrifugation at 12,000 g for $30 \mathrm{~min}$ at $4^{\circ} \mathrm{C}$, the supernatant was gathered. Cryovial test tubes $(2 \mathrm{~mL})$ were used as the center wells each containing $0.5 \mathrm{~mL}$ of $1 \%$ zinc acetate as trapping solution and a filter paper of $2.0-2.5 \mathrm{~cm}^{2}$ to increase the air/liquid contacting surface. The reaction mixture contained 100 $\mathrm{mmol} / \mathrm{L}$ Phosphate Buffer (PH7.4), $10 \mathrm{mmol} / \mathrm{L} \mathrm{L}$-cysteine, $2 \mathrm{mmol} / \mathrm{L}$ pyridoxal 5'-phosphate, and 10\% (w/v) tissue homogenate and was added into the Erlenmeyer flask. The flasks containing reaction mixture and center wells were flushed with N2 before being sealed with a double layer of parafilm. Reaction was initiated by a thermostatic water bath for $90 \mathrm{~min}$ at $37^{\circ} \mathrm{C}$ and was stopped by addition of $0.5 \mathrm{~mL}$ of $20 \%$ trichloroacetic acid. The flasks were sealed again and incubated at $37^{\circ} \mathrm{C}$ for $60 \mathrm{~min}$ in the shaking water to ensure a complete trapping of the $\mathrm{H}_{2} \mathrm{~S}$ released from the mixture. The content of $\mathrm{H}_{2} \mathrm{~S}$ in the solution was measured by Sulphur ion-selective electrode (Unisense, Aarhus, Denmark) and the $\mathrm{H}_{2} \mathrm{~S}$ production was expressed as unit $\mathrm{nmol} / \mathrm{min} / \mathrm{mg}$ protein.

\section{Statistical analysis}

Data are expressed as mean \pm S.E.M. The significance of inter-group differences was evaluated by two-way analyses of variance (ANOVA: Least-significant difference test). Statistical significance was considered at $\mathrm{P}<0.05$.

\section{ACKNOWLEDGMENTS}

This study was supported by National Natural Science Foundation of China (81671057), Zhengxiang Scholar Program of University of South China (2014-004), and the construct program of the key discipline in Hunan province.

\section{CONFLICTS OF INTEREST}

The authors declare that the research was conducted in the absence of any commercial or financial relationships that could be construed as a potential conflicts of interest.

\section{REFERENCES}

1. Tuzcu M, Baydas G. Effect of melatonin and vitamin E on diabetes-induced learning and memory impairment in rats. Eur J Pharmacol. 2006; 537:106-110.

2. Bhutada P, Mundhada Y, Bansod K, Bhutada C, Tawari S, Dixit P, Mundhada D. Ameliorative effect of quercetin on memory dysfunction in streptozotocin-induced diabetic rats. Neurobiol Learn Mem. 2010; 94:293-302.

3. Ahmad W. Overlapped metabolic and therapeutic links between Alzheimer and diabetes. Mol Neurobiol. 2013; 47:399-424.

4. Brismar T, Maurex L, Cooray G, Juntti-Berggren L, Lindstrom P, Ekberg K, Adner N, Andersson S. Predictors of cognitive impairment in type 1 diabetes. Psychoneuroendocrinology. 2007; 32:1041-1051.

5. Saravia F, Revsin Y, Lux-Lantos V, Beauquis J, HomoDelarche F, De Nicola AF. Oestradiol restores cell proliferation in dentate gyrus and subventricular zone of streptozotocin-diabetic mice. J Neuroendocrinol. 2004; 16:704-710.

6. Munshi M, Grande L, Hayes M, Ayres D, Suhl E, Capelson $\mathrm{R}$, Lin S, Milberg W, Weinger K. Cognitive dysfunction is associated with poor diabetes control in older adults. Diabetes Care. 2006; 29:1794-1799.

7. Gaspar JM, Baptista FI, Galvao J, Castilho AF, Cunha RA, Ambrosio AF. Diabetes differentially affects the content of exocytotic proteins in hippocampal and retinal nerve terminals. Neuroscience. 2010; 169:1589-1600. 
8. Zhao CH, Liu HQ, Cao R, Ji AL, Zhang L, Wang F, Yang RH. Effects of dietary fish oil on learning function and apoptosis of hippocampal pyramidal neurons in streptozotocin-diabetic rats. Brain Res. 2012; 1457:33-43.

9. Biessels GJ, Kerssen A, de Haan EH, Kappelle LJ. Cognitive dysfunction and diabetes: implications for primary care. Prim Care Diabetes. 2007; 1:187-193.

10. Wang R. Physiological implications of hydrogen sulfide: a whiff exploration that blossomed. Physiol Rev. 2012; 92:791-896.

11. Kamoun P. Endogenous production of hydrogen sulfide in mammals. Amino Acids. 2004; 26:243-254.

12. Tan BH, Wong PT, Bian JS. Hydrogen sulfide: a novel signaling molecule in the central nervous system. Neurochem Int. 2010; 56:3-10.

13. $\mathrm{Hu} \mathrm{LF}, \mathrm{Lu}$ M, Hon Wong PT, Bian JS. Hydrogen sulfide: neurophysiology and neuropathology. Antioxid Redox Signal. 2011; 15:405-419.

14. Zhang H, Gao Y, Zhao F, Dai Z, Meng T, Tu S, Yan Y. Hydrogen sulfide reduces mRNA and protein levels of betasite amyloid precursor protein cleaving enzyme 1 in PC12 cells. Neurochem Int. 2011; 58:169-175.

15. Kimura H. Hydrogen sulfide induces cyclic AMP and modulates the NMDA receptor. Biochem Biophys Res Commun. 2000; 267:129-133.

16. Giuliani D, Ottani A, Zaffe D, Galantucci M, Strinati F, Lodi R, Guarini S. Hydrogen sulfide slows down progression of experimental Alzheimer's disease by targeting multiple pathophysiological mechanisms. Neurobiol Learn Mem. 2013; 104:82-91.

17. Gong QH, Wang Q, Pan LL, Liu XH, Huang H, Zhu YZ. Hydrogen sulfide attenuates lipopolysaccharide-induced cognitive impairment: a pro-inflammatory pathway in rats. Pharmacol Biochem Behav. 2010; 96:52-58.

18. Brancaleone V, Roviezzo F, Vellecco V, De Gruttola L, Bucci M, Cirino G. Biosynthesis of $\mathrm{H} 2 \mathrm{~S}$ is impaired in non-obese diabetic (NOD) mice. Br J Pharmacol. 2008; 155:673-680.

19. Jain SK, Bull R, Rains JL, Bass PF, Levine SN, Reddy S, McVie R, Bocchini JA. Low levels of hydrogen sulfide in the blood of diabetes patients and streptozotocin-treated rats causes vascular inflammation? Antioxid Redox Signal. $2010 ; 12: 1333-1337$

20. Szabo C. Roles of hydrogen sulfide in the pathogenesis of diabetes mellitus and its complications. Antioxid Redox Signal. 2012; 17:68-80.

21. Yamamoto J, Sato W, Kosugi T, Yamamoto T, Kimura T, Taniguchi S, Kojima H, Maruyama S, Imai E, Matsuo S, Yuzawa Y, Niki I. Distribution of hydrogen sulfide $(\mathrm{H}(2)$ S)-producing enzymes and the roles of the $\mathrm{H}(2) \mathrm{S}$ donor sodium hydrosulfide in diabetic nephropathy. Clin Exp Nephrol. 2013; 17:32-40.

22. El-Seweidy MM, Sadik NA, Shaker OG. Role of sulfurous mineral water and sodium hydrosulfide as potent inhibitors of fibrosis in the heart of diabetic rats. Arch Biochem Biophys. 2011; 506:48-57.

23. Liu F, Chen DD, Sun X, Xie HH, Yuan H, Jia W, Chen AF. Hydrogen sulfide improves wound healing via restoration of endothelial progenitor cell functions and activation of angiopoietin-1 in type 2 diabetes. Diabetes. 2014; 63:1763-1778.

24. Gaut JR, Hendershot LM. The modification and assembly of proteins in the endoplasmic reticulum. Curr Opin Cell Biol. 1993; 5:589-595.

25. Fonseca SG, Burcin M, Gromada J, Urano F. Endoplasmic reticulum stress in beta-cells and development of diabetes. Curr Opin Pharmacol. 2009; 9:763-770.

26. Boyce M, Yuan J. Cellular response to endoplasmic reticulum stress: a matter of life or death. Cell Death Differ. 2006; 13:363-373.

27. Leuner B, Gould E. Structural plasticity and hippocampal function. Annu Rev Psychol. 2010; 61:111-140, C111-113.

28. Lagali PS, Corcoran CP, Picketts DJ. Hippocampus development and function: role of epigenetic factors and implications for cognitive disease. Clin Genet. 2010; 78:321-333.

29. Zhang X, Xu L, He D, Ling S. Endoplasmic reticulum stress-mediated hippocampal neuron apoptosis involved in diabetic cognitive impairment. Biomed Res Int. 2013; 2013:924327.

30. Xie L, Tiong CX, Bian JS. Hydrogen sulfide protects SH-SY5Y cells against 6-hydroxydopamine-induced endoplasmic reticulum stress. Am J Physiol Cell Physiol. 2012; 303:C81-C91.

31. Wei H, Zhang R, Jin H, Liu D, Tang X, Tang C, Du J. Hydrogen sulfide attenuates hyperhomocysteinemiainduced cardiomyocytic endoplasmic reticulum stress in rats. Antioxid Redox Signal. 2010; 12:1079-1091.

32. Wei HJ, Xu JH, Li MH, Tang JP, Zou W, Zhang P, Wang L, Wang CY, Tang XQ. Hydrogen sulfide inhibits homocysteine-induced endoplasmic reticulum stress and neuronal apoptosis in rat hippocampus via upregulation of the BDNF-TrkB pathway. Acta Pharmacol Sin. 2014; 35:707-715.

33. Cardoso S, Carvalho C, Santos R, Correia S, Santos MS, Seica R, Oliveira CR, Moreira PI. Impact of STZ-induced hyperglycemia and insulin-induced hypoglycemia in plasma amino acids and cortical synaptosomal neurotransmitters. Synapse. 2011; 65:457-466.

34. Whishaw IQ. Place learning in hippocampal rats and the path integration hypothesis. Neurosci Biobehav Rev. 1998; 22:209-220.

35. Reiffenstein RJ, Hulbert WC, Roth SH. Toxicology of hydrogen sulfide. Annu Rev Pharmacol Toxicol. 1992; 32:109-134.

36. Beauchamp RO Jr, Bus JS, Popp JA, Boreiko CJ, Andjelkovich DA. A critical review of the literature on hydrogen sulfide toxicity. Crit Rev Toxicol. 1984; 13:25-97. 
37. Abe K, Kimura H. The possible role of hydrogen sulfide as an endogenous neuromodulator. J Neurosci. 1996; 16:1066-1071.

38. Morris R. Developments of a water-maze procedure for studying spatial learning in the rat. J Neurosci Methods. 1984; $11: 47-60$

39. Oades R, Taghzouti K, Simon H, Le Moal M. Dopaminesensitive alternation and collateral behaviour in a Y-maze: effects of d-amphetamine and haloperidol. Psychopharmacology (Berl). 1985; 85:123-128.

40. Lainiola M, Procaccini C, Linden AM. mGluR3 knockout mice show a working memory defect and an enhanced response to MK-801 in the T- and Y-maze cognitive tests. Behav Brain Res. 2014; 266:94-103.

41. Ennaceur A, Delacour J. A new one-trial test for neurobiological studies of memory in rats. 1: behavioral data. Behav Brain Res. 1988; 31:47-59.

42. Araki E, Oyadomari S, Mori M. Impact of endoplasmic reticulum stress pathway on pancreatic beta-cells and diabetes mellitus. Exp Biol Med (Maywood). 2003; 228:1213-1217.

43. Kaufman RJ, Back SH, Song B, Han J, Hassler J. The unfolded protein response is required to maintain the integrity of the endoplasmic reticulum, prevent oxidative stress and preserve differentiation in beta-cells. Diabetes Obes Metab. 2010; 12:99-107.

44. Eichenbaum H. A cortical-hippocampal system for declarative memory. Nat Rev Neurosci. 2000; 1:41-50.

45. Squire LR, Zola SM. Structure and function of declarative and nondeclarative memory systems. Proc Natl Acad Sci U S A. 1996; 93:13515-13522.

46. Henninger N, Feldmann RE Jr, Futterer CD, Schrempp C, Maurer MH, Waschke KF, Kuschinsky W, Schwab S. Spatial learning induces predominant downregulation of cytosolic proteins in the rat hippocampus. Genes Brain Behav. 2007; 6:128-140.

47. Doyle KM, Kennedy D, Gorman AM, Gupta S, Healy SJ, Samali A. Unfolded proteins and endoplasmic reticulum stress in neurodegenerative disorders. J Cell Mol Med. 2011; 15:2025-2039.

48. Li X, Zhang KY, Zhang P, Chen LX, Wang L, Xie M, Wang CY, Tang XQ. Hydrogen sulfide inhibits formaldehydeinduced endoplasmic reticulum stress in PC12 cells by upregulation of SIRT-1. PLoS One. 2014; 9:e89856.
49. Yang G, Yang W, Wu L, Wang R. H2S, endoplasmic reticulum stress, and apoptosis of insulin-secreting beta cells. J Biol Chem. 2007; 282:16567-16576.

50. Yusuf M, Kwong Huat BT, Hsu A, Whiteman M, Bhatia M, Moore PK. Streptozotocin-induced diabetes in the rat is associated with enhanced tissue hydrogen sulfide biosynthesis. Biochem Biophys Res Commun. 2005; 333:1146-1152.

51. Umathe SN, Kochar NI, Jain NS, Dixit PV. Gastrointestinal dysfunction in diabetic rats relates with a decline in tissue L-arginine content and consequent low levels of nitric oxide. Nitric Oxide. 2009; 20:129-133.

52. Huang JN, Wang CY, Wang XL, Wu BZ, Gu XY, Liu WX, Gong LW, Xiao P, Li CH. Tenuigenin treatment improves behavioral Y-maze learning by enhancing synaptic plasticity in mice. Behav Brain Res. 2013; 246:111-115.

53. Breckenridge DG, Germain M, Mathai JP, Nguyen M, Shore GC. Regulation of apoptosis by endoplasmic reticulum pathways. Oncogene. 2003; 22:8608-8618.

54. Cai ZL, Wang CY, Jiang ZJ, Li HH, Liu WX, Gong LW, Xiao P, Li CH. Effects of cordycepin on Y-maze learning task in mice. Eur J Pharmacol. 2013; 714:249-253.

55. Morris RG, Garrud P, Rawlins JN, O'Keefe J. Place navigation impaired in rats with hippocampal lesions. Nature. 1982; 297:681-683.

56. Tiwari V, Kuhad A, Bishnoi M, Chopra K. Chronic treatment with tocotrienol, an isoform of vitamin E, prevents intracerebroventricular streptozotocin-induced cognitive impairment and oxidative-nitrosative stress in rats. Pharmacol Biochem Behav. 2009; 93:183-189.

57. Tiwari V, Kuhad A, Chopra K. Suppression of neuroinflammatory signaling cascade by tocotrienol can prevent chronic alcohol-induced cognitive dysfunction in rats. Behav Brain Res. 2009; 203:296-303.

58. Geng B, Yang J, Qi Y, Zhao J, Pang Y, Du J, Tang C. H2S generated by heart in rat and its effects on cardiac function. Biochem Biophys Res Commun. 2004; 313:362-368.

59. Yang J, Li H, Ochs T, Zhao J, Zhang Q, Du S, Chen Y, Liu P, Wang Y, Feng X, Zhang C, Tang C, Du J, Jin H. Erythrocytic hydrogen sulfide production is increased in children with vasovagal syncope. J Pediatr. 2015; 166:965-969. 